\title{
Surgical Outcomes after Total Colectomy with Ileorectal Anastomosis in Patients with Medically Intractable Slow Transit Constipation
}

\author{
Guiyun Sohn, Chang Sik Yu, Chan Wook Kim, Jae Young Kwak, Tae Young Jang, Kyung Ho Kim, \\ Song Soo Yang, Yong Sik Yoon, Seok-Byung Lim, Jin Cheon Kim \\ Department of Colon and Rectal Surgery, Asan Medical Center, University of Ulsan College of Medicine, Seoul, Korea
}

\begin{abstract}
Purpose: The aim of this study was to evaluate outcomes of a total colectomy with ileorectal anastomosis in patients with slow transit constipation.

Methods: A retrospective review of 37 consecutive patients with slow transit constipation who underwent a total colectomy between 1994 and 2008 was undertaken. Preoperative and postoperative Wexner's constipation scores were collected and used to evaluate the outcomes after surgical treatment. Also patients' postoperative satisfaction scores were collected using a 4 -point scale.

Results: The 37 patients consisted of 31 women and 6 men, with a median age of 41 years (range, 17 to 71 years). Pre- and post-operative Wexner's scores were collected from 33 patients (89.1\%), and the mean preoperative Wexner's score was 19.3 (range, 11 to 24), which decreased to an average post-operative score of 2.3 (range, 0 to 8). Neither intraoperative complications nor postoperative mortalities were noted. Five patients (13.5\%) had early postoperative complications, and the most common complication was postoperative ileus $(10.8 \%)$. Seven patients $(18.9 \%)$ had late postoperative complications, and postoperative ileus $(10.8 \%)$ was also the most common. Twenty seven of 33 patients were satisfied with their surgical outcome $(81.8 \%)$.

Conclusion: A total colectomy with ileorectal anastomosis might be an effective surgical procedure with acceptable morbidity to treat medically intractable slow transit constipation.
\end{abstract}

Keywords: Colonic inertia; Colectomy; Treatment outcome; Postoperative complication

\section{INTRODUCTION}

The prevalence of constipation has been reported to be $2-27 \%$ in Western countries, and the prevalence rate varies depending on the definition used [1]. The mean prevalence in Korea was reported to be $16.5 \%$ [2]. Constipation is observed along with other symp-

Received: March 10, 2011 Accepted: July 15, 2011

Correspondence to: Chang Sik Yu, M.D.

Department of Colon and Rectal Surgery, Asan Medical Center, University of Ulsan College of Medicine, 388-1 Pungnap 2-dong, Songpa-gu, Seoul

138-736, Korea

Tel: +82-2-3010-3494, Fax: +82-2-3010-6701

E-mail: csyu@amc.seoul.kr

(C) 2011 The Korean Society of Coloproctology

This is an open-access article distributed under the terms of the Creative Commons Attribution NonCommercial License (http://creativecommons.org/licenses/by-nc/3.0) which permits unrestricted noncommercial use, distribution, and reproduction in any medium, provided the original work is properly cited. toms in many cases, and the subjective meaning of constipation is different by individuals, but it means mainly a low frequency of defecation, a small amount of stool, strain during defecation, hard stool and a sensation of incomplete evacuation [3-5].

Chronic constipation affects the health of patients and is related with serious psychological stress. Medical treatments generally improve its symptoms in most cases, but a few patients do not respond to conservative treatments and need additional ones.

Constipation can be classified into three groups through anorectal physiological studies: 1) the normal transit constipation group without abnormality in the anorectal physiological studies; 2) the slow transit constipation group with a decrease in overall bowel movement; and 3) the obstructive defecation or outlet obstruction group with pelvic floor dyssynergia (or dyssynergic defecation), showing functional obstruction without any anatomical abnormality in the anorectal area or with inadequate defecatory propulsion [6]. 
When the overall colonic transit time is delayed in a colonic transit time study, slow transit constipation can be diagnosed, and it can be an indication of a need for surgical treatment. Surgical treatments include an antegrade colonic enema [7], a total colectomy and ileorectal anastomosis or caecorectal anastomosis, a partial colectomy, a total proctocolectomy and ileal pouch-anal anastomosis, and total colectomy and ileorectal anastomosis, and among these procedures, a total colectomy and ileorectal anastomosis have been most widely used. Thus, this study aimed to investigate the surgical outcomes of total colectomies in patients with medically intractable slow transit constipation.

\section{METHODS}

This study analyzed 37 patients with slow transit constipation who underwent a colectomy in the Colorectal Department of Asan Medical Center from January 1994 to December 2008. Three of the 37 patients did not visit the outpatient clinic after surgery, and when the follow-up of one patient at the outpatient clinic was finished, the patient's phone number and address were changed. Thus, the postoperative course could be observed only in the other $33 \mathrm{pa}-$ tients. The mean follow-up period of the patients was 41.2 months (range, 0 to 150.3 months). This study defined constipation based on 'Rome III criteria' (Table 1) [8]

The symptoms of the patients were objectively assessed with the Wexner score through history taking [9]. Patients' subjective satisfaction after the surgery was evaluated using a four-point scale (1 point, poor; 2 points, fair; 3 points, good; 4 points, excellent); neurologic disease and endocrine disease causing constipation secondarily were also investigated. After anatomical obstruction had been checked through digital rectal examination, colonoscopy or barium enema, and abdominal and pelvic computed tomography, patients without any abnormalities in these examinations underwent a colonic transit time study, anorectal manometry, defecography and a balloon expulsion test. The colonic transit time was measured in 30 patients; it was not measured in five patients who had emergency surgery due to stercoral colitis and in two patients who could not defecate at all. The patients undergoing emergency surgery because of stercoral colitis had been unable to defecate for a long time before their admissions to the emergency room and none of the patients who could not take the colonic transit time study because they did not defecate were able to defecate even after medical treatment in the hospital. In 33 cases, excluding 4 of the 5 receiving emergency surgery, anorectal manometry was conducted.

Among patients suffering from constipation for over one year without any response to medical treatment, surgery was conducted only when the colonic transit time was delayed in the colonic transit time study or when patients with slow transit constipation combined with pelvic outlet obstruction had no response to biofeedback therapy; patients without rectoanal inhibitory reflex were excluded.

The preoperative and the postoperative data were collected from the medical records of the subjects, and insufficient data, the current defecatory function and the satisfaction with the surgery were collected through additional telephone interviews. Statistical analysis was conducted with the paired t-test, and a P-value of less than 0.05 was considered to be significant. The statistical program used in this study was SPSS ver.12.0 (SPSS Inc., Chicago, IL, USA).

\section{RESULTS}

\section{Clinical characteristics of patients}

Thirty-one (83.7\%) out of 37 patients were females. The patients had symptoms such as abdominal distension, sensation of incomplete evacuation and severe weight loss due to decreased oral intake following constipation before the surgery. In addition, their social lives and daily lives were restricted because these symptoms or long-term medication affected their lives at work and at school. Three patients were taking medication for depression and one for insomnia.

The mean age at surgery was 41 years (range, 17 to 71 years). The Wexner score calculated based on preoperative symptoms could be obtained in 33 patients (89.2\%), and it was 19.3 points on average (range, 11 to 24 points) (Table 2). The duration of symptoms was on average 124 months (range, 12 to 360 months).

All of the 37 patients underwent total a colectomy and ileorectal

Table 1. Diagnostic criteria ${ }^{a}$ of functional constipation (Rome III)

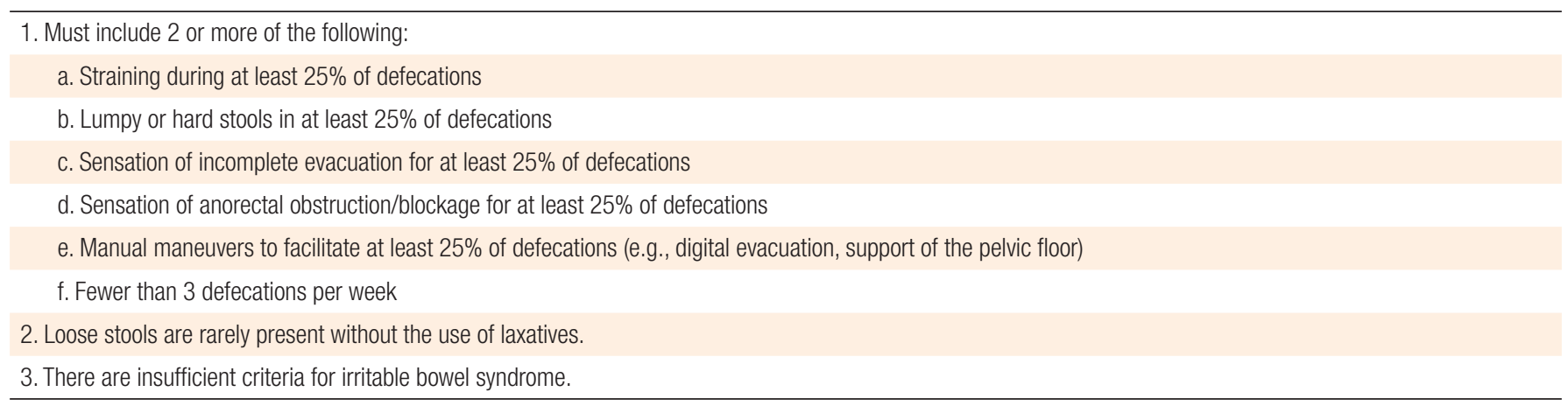

${ }^{a}$ Criteria fulfilled for the last 3 months with symptom onset at least 6 months prior to the diagnosis. 
Table 2. Wexner constipation score

\begin{tabular}{|c|c|}
\hline $\begin{array}{l}\text { Constipation scoring system } \\
\text { (minimum 0, maximum score 30) }\end{array}$ & Score \\
\hline \multicolumn{2}{|l|}{ Frequency of bowel movements } \\
\hline 1-2 times per $1-2$ days & 0 \\
\hline 2 times per week & 1 \\
\hline Once per week & 2 \\
\hline Less than once per week & 3 \\
\hline Less than once per month & 4 \\
\hline \multicolumn{2}{|l|}{ Difficulty: painful evacuation effort } \\
\hline Never & 0 \\
\hline Rarely & 1 \\
\hline Sometimes & 2 \\
\hline Usually & 3 \\
\hline Always & 4 \\
\hline \multicolumn{2}{|c|}{ Completeness: feeling incomplete evacuation } \\
\hline Never & 0 \\
\hline $1-3$ & 1 \\
\hline $3-6$ & 2 \\
\hline $6-9$ & 3 \\
\hline More than 9 & 4 \\
\hline \multicolumn{2}{|l|}{ Pain: abdomen } \\
\hline Never & 0 \\
\hline Rarely & 1 \\
\hline Sometimes & 2 \\
\hline Usually & 3 \\
\hline Always & 4 \\
\hline \multicolumn{2}{|l|}{ Time: minutes in lavatory per attempt } \\
\hline Less than 5 & 0 \\
\hline $5-10$ & 1 \\
\hline $10-20$ & 2 \\
\hline $20-30$ & 3 \\
\hline More than 30 & 4 \\
\hline \multicolumn{2}{|l|}{ History: duration of constipation (yr) } \\
\hline 0 & 0 \\
\hline $1-5$ & 1 \\
\hline $5-10$ & 2 \\
\hline $10-20$ & 3 \\
\hline More than 20 & 4 \\
\hline \multicolumn{2}{|l|}{ Assistance: type of assistance } \\
\hline Without assistance & 0 \\
\hline Stimulative laxatives & 1 \\
\hline Digital assistance/enema & 2 \\
\hline
\end{tabular}

Table 3. Clinical characteristics

\begin{tabular}{lc}
\hline Age (yr) & $41(17-71)^{\mathrm{a}}$ \\
Gender (n) & $31 / 6$ \\
$\quad$ Male/female & \\
Operation (n) & 37 \\
Total colectomy \& ileorectal anastomosis & \\
$\quad$ Auxiliary procedure & 1 \\
$\quad$ Rectopexy & $203 \pm 86.7$ \\
Operation time (min) & \\
Hospital stay (day) & $12(8-29)^{\mathrm{a}}$ \\
Follow-up duration (mo) & $124(2.6-150.3)^{\mathrm{a}}$ \\
\hline
\end{tabular}

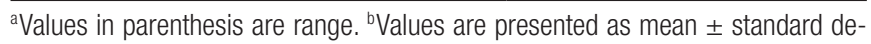
viation.

Table 4. Segmental colonic transit time

\begin{tabular}{lc}
\hline Colonic segment & Mean \pm standard error $(\mathrm{hr})$ \\
\hline Ascending & $40.8 \pm 5.71$ \\
Descending & $41.2 \pm 4.50$ \\
Rectosigmoid & $25.4 \pm 7.21$ \\
Total & $107.4 \pm 8.80$ \\
\hline
\end{tabular}

Table 5. Findings of preoperative manometry

\begin{tabular}{lc}
\hline & Mean \pm standard error \\
\hline Sphincter function & \\
Maximal resting pressure $(\mathrm{mmHg})$ & $69.23 \pm 7.66$ \\
Maximal squeeze pressure $(\mathrm{mmHg})$ & $149.46 \pm 10.79$ \\
Rectal sensory thresholds & \\
Minimal sensory volume $(\mathrm{mL})$ & $11.52 \pm 0.88$ \\
Maximal tolerable volume $(\mathrm{mL})$ & $156.21 \pm 10.95$ \\
Rectal compliance $(\mathrm{mL} / \mathrm{mmHg})$ & $3.04 \pm 0.44$ \\
\hline
\end{tabular}

anastomosis. The colon was resected at the level of the sacral promontory considered as the rectosigmoid junction; then, a side-toend stapled anastomosis was performed. In one case, an ileostomy was added due to contamination caused by fecaloma during surgery, and an ileostomy take down was performed at nine months after initial operation. The mean operation time was $203 \pm 86.7$ minutes, and the median length of hospital stay was 12 dyas (range, 8 to 29 days) (Table 3 ).

A preoperative colonic transit time study showed that the transit time was delayed in all subjects (Table 4, Fig. 1) and that patients with obstructive defecation did not respond to biofeedback therapy. In addition, anorectal manometry found no abnormalities in the resting and the squeezing pressures or rectal sense, and the rectoanal inhibitory reflex was observed in all 33 cases (Table 5). 

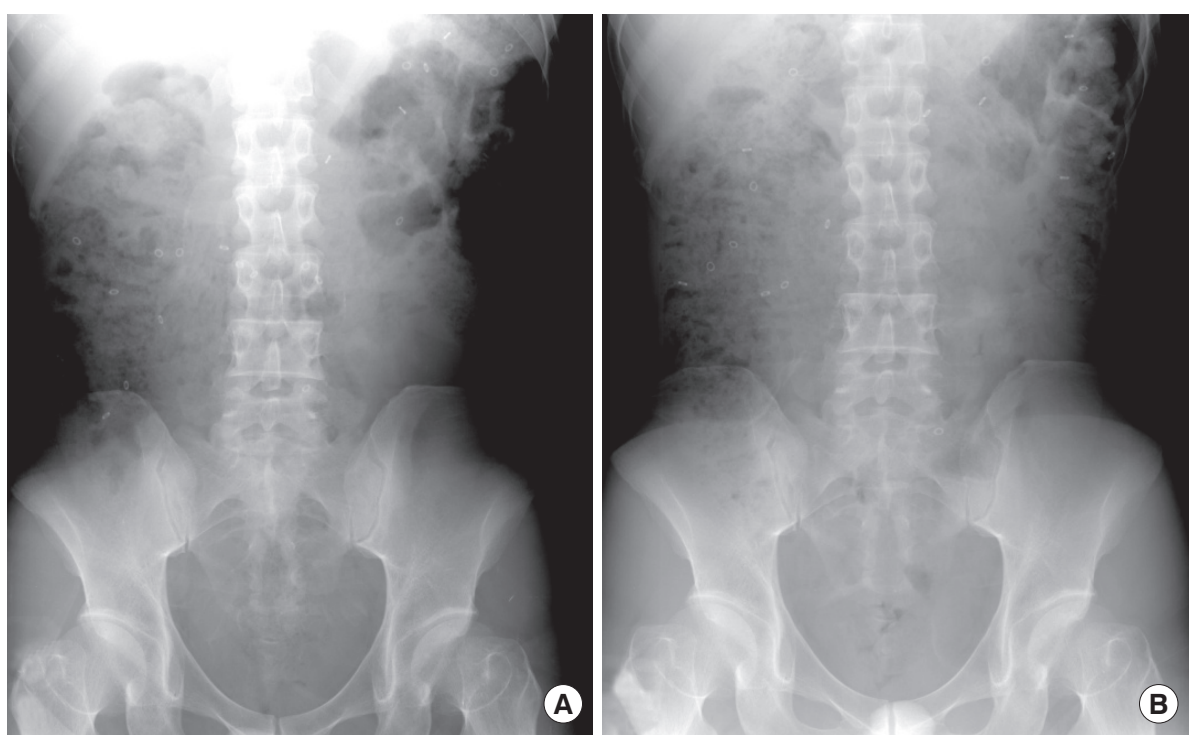

Fig. 1. (A) Delayed colonic transit time 1 day after radio-opaque markers ingestion. (B) Delayed colonic transit time 5 days after radio-opaque marker ingestion. Diffusely scattered radio-opaque markers are seen throughout entire colon.

\section{Postoperative complications}

There were no mortalities after surgery. Early complications within one month after surgery were observed in five patients (13.5\%). The most common complication was intestinal obstruction which was found in four patients (10.5\%), and one of them (2.6\%) had a wound infection associated with an intestinal obstruction. The fifth patient had an intraabdominal abscess. All five patients were hospitalized for conservative treatment and were discharged after successful treatment.

Seven patients (18.9\%) had late complications during follow-up. The most frequent late complication was also intestinal obstruction. Four patients $(10.8 \%)$ had intestinal obstruction, and two of them were improved after conservative treatment while the other two needed surgical treatment. One of the two patients needing surgical treatment underwent adhesiolysis, and the other one received a small bowel resection and anastomosis, as well as adhesiolysis, because the intestinal obstruction had progressed to small bowel strangulation. Among the other three patients with late complications, one patient had a small bowel resection and anastomosis due to an enterocutaneous fistula caused by small bowel stump leakage, another patient had an ileorectal bypass due to anastomosis stricture and microperforation, and the third had anastomotic leakage, but was improved after conservative treatment (Table 6). Although patients with intestinal obstruction as an early complication did not have obstruction again during long-term follow-up, one patient with intraperitoneal fluid collection as an early complication had an enterocutaneous fistula during long-term followup and had a small bowel resection and anastomosis.

\section{Postoperative histopathologic examination}

Postoperative pathology showed decreased ganglion cell number in 31 patients (83.8\%) (Fig. 2). Segmental ganglion cell numbers per $\mathrm{cm} 2$ of 19 patients were reported separately for the ascending,
Table 6. Postoperative complications \& management

\begin{tabular}{lll}
\hline Complications & \multicolumn{1}{c}{ Management } & No. (\%) \\
\hline Early ( $\leq 1 \mathrm{mo})$ & & $5(13.5)$ \\
Postoperative ileus & Conservative & $4(10.8)$ \\
Wound infection & Conservative & $1(2.7)$ \\
Intraabdominal abscess & Conservative & $1(2.7)$ \\
Late ( $\geq 1 \mathrm{mo})$ & & $7(18.9)$ \\
Ileus & & $4(10.8)$ \\
& Conservative & $2(5.4)$ \\
& Operation (adhesiolysis) & $1(2.7)$ \\
Anastomosis stricture & Operation (SB R\&A) & $1(2.7)$ \\
Eneterocutaneous fistula & Operation (ileorectal bypass) & $1(2.7)$ \\
Anastomosis leakage & Operation (SB R\&A) & $1(2.7)$ \\
\hline
\end{tabular}

SB R\&A, small bowel resection and anastomosis.

descending and sigmoid colon, and their average numbers were $14 / \mathrm{cm}^{2}, 13 / \mathrm{cm}^{2}$ and $14 / \mathrm{cm}^{2}$ respectively. Because the ganglion cell numbers of the control group with normal colonic transit time were $25 / \mathrm{cm}^{2}, 27 / \mathrm{cm}^{2}$ and $23 / \mathrm{cm}^{2}$, respectively [10], the ganglion cell numbers from slow transit constipation patients were somehow decreased. In addition, melanosis coli was shown in three patients.

\section{Postoperative Wexner score}

The postoperative defecatory function was assessed in 33 of the 37 patients. The mean number of postoperative bowel movements was 3.6 times per day, and the average postoperative Wexner score was 2.1 points (range, 0 to 8 points). The average preoperative Wexner score was 19.3, and this difference between postoperative and pre- 

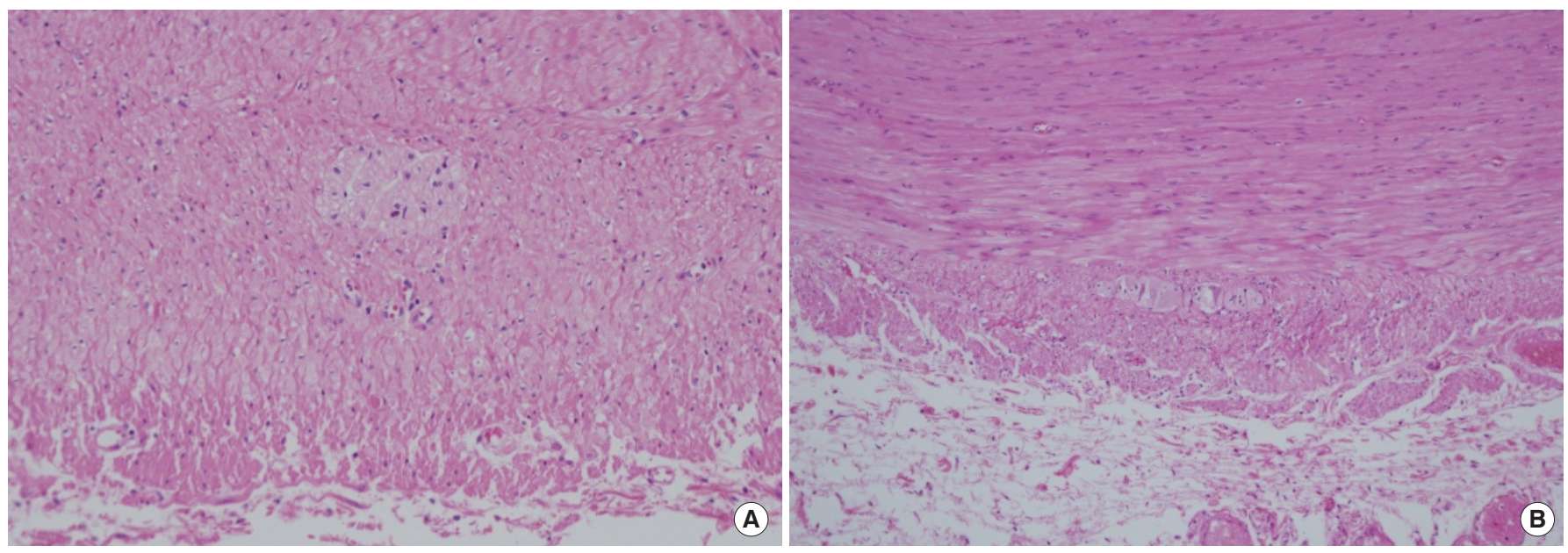

Fig. 2. (A) Hypoganglinosis and aggregated abnormal ganglions in the myenteric plexus $(\mathrm{H} \& \mathrm{E}, \times 400)$. (B) Thickened proper muscle and hypoganglinosis in the myenteric plexus $(\mathrm{H} \& \mathrm{E}, \times 400)$.

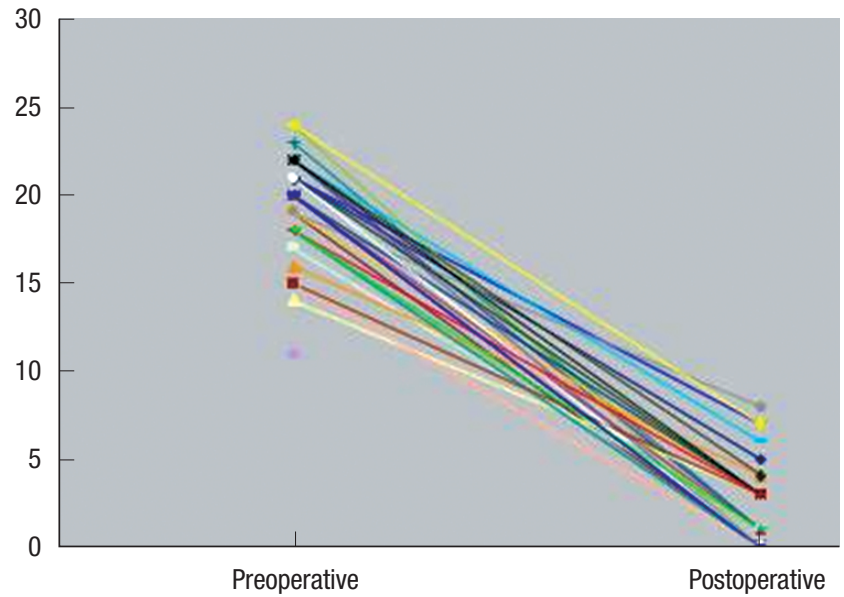

Fig. 3. Change of Wexner's constipation scores for the preoperative and the postoperative periods (total).

operative Wexner scores was statistically significant $(\mathrm{P}<0.001)$ (Fig. 3).

The postoperative Wexner score was investigated by symptoms. As 11 (33\%) patients experienced pain during defecation, it was the most common symptom that persisted even after the surgery. Out of those 11 patients, eight patients felt the pain 2-3 times per week, two patients felt the pain 2-3 times per month, and one patient felt the pain once per day. However, no patient needed a reoperation or medication due to pain. After the surgery, defecation took approximately five minutes, 5-10 minutes and 20-30 minutes in four patients $(12.1 \%)$, three patients and one patient, respectively. Three patients $(9.0 \%)$ felt the sensation of incomplete evacuation even after the surgery, and they experienced it approximately once per day, two to three times per week, and two to three times per month, respectively.

Out of the 33 patients, three $(9.1 \%)$ had diarrhea more than ten
Table 7. Postoperative patients'satisfaction score

\begin{tabular}{lc}
\hline Satisfaction scale (point) & No. (\%) \\
\hline Excellent (4) & $16(48.5)$ \\
Good (3) & $11(33.3)$ \\
Fair (2) & $6(18.2)$ \\
Poor (1) & $0(0)$ \\
\hline
\end{tabular}

times per day. While one patient was not improved after taking antidiarrheal medication, the other two had no serious difficulty without antidiarrheal medication.

\section{Patients' satisfaction with surgery}

Thirty-three out of the 37 patients were satisfied were with the postoperative outcome. Out them, 16 (48.5\%), 11 (33.3\%), and 6 (18.2\%) answered 4 (excellent), 3 (good), and 2 (fair) points, respectively, and no patient reported one point (poor). Therefore, 27 patients (81.9\%) were quite satisfied with the postoperative outcome, and all 33 patients said that their symptoms, such abdominal distension, were improved postoperatively (Table 7). Three of the six patients who reported 2 (fair) points pointed to postoperative diarrhea as the reason for their low satisfaction; their average frequency of diarrhea was five times per day.

\section{DISCUSSION}

Although the causes of slow transit constipation have not been determined, the possibility that the disease may be due to enteric neuropathy caused by abnormality of the enteric nervous system has been suggested continuously [11]. Pathologic examinations of surgically-treated severe slow transit constipation patients have consistently revealed a decrease in neurons or neurofilaments [12, $13]$, and this abnormality is considered to be related to a decrease 
in the interstitial cell of Cajal (ICC), which is recognized as an intestinal pacemaker [10]. One report insisted that an increase and a decrease in neuropeptides, such as nitric oxide synthase, vasoactive intestinal peptide (VIP) and substance $\mathrm{P}$, had a correlation with bowel movement, and another said that enterochromaffin cells and serotonin secreting cells were abnormally reduced in constipation patients $[14,15]$. These results are similar to the findinga of this study in that the ganglion cell number was lower in 31 of the 37 patients. Yu et al. [10] compared the number of ganglion cells and ICC of 10 patients who underwent a total colectomy due to hereditary nonpolyposis colonic cancer or familial adenomatous polyposis with that of patients who had a total colectomy due to chronic idiopathic constipation and reported that the number of ganglion cell and ICC in patients with chronic idiopathic constipation was decreased.

In this study, all subjects had a history of taking laxatives before the surgery, which could lead to changes in tissues [16]. Among laxatives, anthraquinones like senna, cascara, sagrada, aloe and rhubarb are frequently observed in foods or health supplements for constipation on the market and in easily-purchased medications for constipation. Long-term administration of anthraquinones can lead to melanosis coli and can decrease type-1 neurosecretory granules. Smooth muscle atrophy, local Schwann cell proliferation and abnormalities of axons and dendrites were also found.

In patients with slow transit constipation, no response to medical treatments is an indication for surgery. When the colonic transit time is delayed, slow transit constipation is the diagnosis, and when combined with pelvic outlet obstruction, surgery is considered only in patients showing no response to biofeedback therapy. Thus, if radio-opaque markers remain in the rectum and the sigmoid colon after the colonic transit time study, surgical treatment should be avoided, or a surgical correction of a pelvic outlet obstruction can be added to surgery for slow transit constipation. In this study, one patient had a rectal prolapse on the colonic transit time study, and defecography and a total colectomy were performed along with a posterior rectopexy using Marlex mesh.
Antroduodenal and esophageal manometry, a gastric emptying study, a small bowel transit study and a hydrogen breath test are conducted preoperatively to check the upper gastrointestinal motility. Although an ileostomy is known to be relatively effective surgery in patients with diffuse abnormality of gastrointestinal motility, its performance, surgical techniques and effects are still controversial. For slow transit constipation combined with abnormal upper gastrointestinal motility, Redmond et al. [17] found that the success rate of a total colectomy was $90 \%$ in slow transit constipation patients with only colon transit abnormality, but it dropped to $13 \%$ in patients with a diffuse abnormality of gastrointestinal motility. On the contrary, Pemberton et al. [18] reported that four out of 36 constipation patients receiving a total colectomy had a pseudo-obstruction on gastrointestinal manometry, and all of them showed satisfactory surgical outcomes. In addition, Glia et al. [19] revealed that a subtotal colectomy for slow transit constipation associated with abnormality of bowel movement improved symptoms in $86 \%$ of 17 cases and that the result of antroduodenal manometry was an important prognostic factor. In this study, the upper gastrointestinal motility test was not a routine test for all patients, but an additional test only in patients suspected of having abnormal upper gastrointestinal motility because radio-opaque markers did not descend to the colon through the upper gastrointestinal tract in the colonic transit time study. As no one was considered to have abnormal upper gastrointestinal motility in the preoperative colonic transit time test in this study, the additional test was not conducted. Moreover, symptoms were relieved in all patients after the surgery, so no patient was thought to have an upper gastrointestinal abnormality.

Surgical treatments for slow transit constipation are a total colectomy and ileorectal anastomosis and a subtotal colectomy and ileosigmoid colon anastomosis or caecorectal anastomosis. Currently, a total colectomy and ileorectal anastomosis are known to be more successful than a subtotal colectomy and ileo-sigmoid colon anastomosis [20]. Some remaining sigmoid colon can cause a recurrence of constipation, but anastomosis below $7-10 \mathrm{~cm}$ from the

Table 8. Postoperative functional outcomes and patients' satisfaction

\begin{tabular}{lcccc}
\hline Author & Year & No. & Bowel movement/day (mean) & Satisfaction (\%) \\
\hline Vasilevsky [20] & 1988 & 51 & 2.8 & 71 \\
Pemberton [18] & 1991 & 38 & 3 & 100 \\
Piccirillo [30] & 1995 & 54 & 5 & 94 \\
Platell [31] & 1996 & 96 & 4 & 82 \\
Lubowski [32] & 1996 & 52 & 4 & 90 \\
Nyam [21] & 1997 & 74 & 2.1 & 87 \\
Bernini [33] & 1998 & 106 & - & 56 \\
Hasegawa [34] & 1998 & 76 & - & 39 \\
Hassan [35] & 2006 & 59 & 3.6 & 85 \\
Present study & 2010 & 37 & & 82 \\
\hline
\end{tabular}


anal verge can produce diarrhea and fecal incontinence. A partial colectomy preserving the appendix and the ileocecal valve was also found to produce a low success rate [21]. Outcomes of a total colectomy for slow transit constipation were reported differently in many studies. The success rate for a total colectomy and ileorectal anastomosis for slow transit constipation has been shown to be around $90 \%$ overall, and they have been preferred because the postoperative complication rate and the postoperative morbidity rate are low [22]. However, the satisfaction of patients after a colectomy has varied from $39 \%$ to $100 \%$, and the postoperative defecation frequency has been reported to be 1.4-5 times (Table 8). When the megarectum is associated, a restorative proctocolectomy using an ileal pouch should be conducted after removing all of the dilated rectum. Nicholls and Kamm [23] reported that in two patients with persistent constipation. even after total colectomy, the remaining rectum was removed, and an ileal pouch-anal anastomosis was performed, reducing the defecation frequency to 2-3 times per day.

Arbuthnot Lane suggested total colectomy and ileorectal anastomosis for constipation in 1908, but they were not widely performed due to a high morbidity rate and a high mortality rate. In addition, some studies reported a high postoperative complication rate [24, 25]. Knowles et al. [26] analyzed 31 research papers published from 1981 to 1998 and found that the rates of small bowel obstruction and reoperation were $18 \%$ and $14 \%$, respectively. Pikarsky et al. [27] said that the reoperation rate was $10 \%$ in their study conducted with 30 patients, and FitzHarris et al. [28] reported that adhesiolysis, permanent ileostomy and anastomosis revision were needed in $17 \%, 4 \%$, and $7 \%$ of the patients, respectively, in their study performed with 75 patients. In this study, four (10.8\%) patients underwent reoperation, and four (10.8\%) patients had intestinal obstruction. The rates were similar to those in other studies.

Knowles et al. [26] reported that the success rate of a colectomy for constipation was $86 \%$ (range, 39 to $100 \%$ ), and Pinedo et al. [29] revealed that the mean Wexner score declined from 22.3 to 1.8 after a laparoscopic total colectomy in 20 patients with slow transit constipation. He also reported that constipation of all 33 patients undergoing surgery was improved and that the success rate was $90.9 \%$ as three patients experienced diarrhea over 10 times per day. The mean Wexner score also became lower, decreased from 19.3 to 2.06, after the surgery. However, the postoperative Wexner score used in this study was obtained from the data in the medical records of outpatients at our hospital or from telephone interview, so the data were not collected during the same follow-up period for all patients. Because a patient's symptoms can change during the follow-up period, the Wexner score can also change during the period. Thus, long-term follow-up and evaluation are considered to be necessary in the future. Like most studies with similar purposes, this study determined the success rate of the surgery based on postoperative defecation frequency, and it assessed satisfaction with the surgery through telephone interviews. Out of the 33 patients, 27 (81.8\%) were satisfied with their surgical outcomes. All of the six patients answering "fair" to a question about surgical out- come said that their symptoms were improved compared to their preoperative status.

In this study, three $(9.1 \%)$ of the 33 patients had diarrhea over 10 times per day. Knowles et al. [26] analyzed 31 research papers reporting on patients receiving a colectomy for constipation and revealed that postoperative fecal incontinence and diarrhea were observed in 16 papers; the mean rate of occurrences of these symptoms was $14 \%$ (range, 0 to $52 \%$ ). This level is similar to that of our study. Pemperton et al. [18] investigated 277 patients undergoing a subtotal colectomy and insisted that the reason for no case of diarrhea and fecal incontinence, unlike other studies was because the subjects did not include irritable bowel syndrome patients.

In this study, one patient (2.8\%) experienced continuous anal fissure and increased sphincter pressure on anorectal manometry even after the surgery although their constipation symptoms were relieved, so a sphincterotomy was conducted, and the symptoms were improved. This rate is considered to be relatively low compared to the values reported in other studies (9\%).

The results of this study show that a total colectomy and ileorectal anastomosis is considered to be comparatively effective to relieve symptoms of slow transit constipation patients not responding to medical treatments, and patient selection using an anorectal physiology test is important.

\section{CONFLICT OF INTEREST}

No potential conflict of interest relevant to this article was reported.

\section{REFERENCES}

1. Pare P, Ferrazzi S, Thompson WG, Irvine EJ, Rance L. An epidemiological survey of constipation in canada: definitions, rates, demographics, and predictors of health care seeking. Am J Gastroenterol 2001;96:3130-7.

2. Jun DW, Park HY, Lee OY, Lee HL, Yoon BC, Choi HS, et al. A population-based study on bowel habits in a Korean community: prevalence of functional constipation and self-reported constipation. Dig Dis Sci 2006;51:1471-7.

3. Higgins PD, Johanson JF. Epidemiology of constipation in North America: a systematic review. Am J Gastroenterol 2004;99:750-9.

4. D'Hoore A, Penninckx F. Obstructed defecation. Colorectal Dis 2003;5:280-7.

5. Rao SS. Constipation: evaluation and treatment. Gastroenterol Clin North Am 2003;32:659-83.

6. Lembo A, Camilleri M. Chronic constipation. N Engl J Med 2003; 349:1360-8.

7. Malone PS, Ransley PG, Kiely EM. Preliminary report: the antegrade continence enema. Lancet 1990;336:1217-8.

8. Drossman DA. Rome III: the new criteria. Chin J Dig Dis 2006;7: 181-5.

9. Agachan F, Chen T, Pfeifer J, Reissman P, Wexner SD. A constipation scoring system to simplify evaluation and management of con- 
stipated patients. Dis Colon Rectum 1996;39:681-5.

10. Yu CS, Kim HC, Hong HK, Chung DH, Kim HJ, Kang GH, et al. Evaluation of myenteric ganglion cells and interstitial cells of Cajal in patients with chronic idiopathic constipation. Int J Colorectal Dis 2002;17:253-8.

11. Raethjen J, Pilot MA, Knowles C, Warner G, Anand P, Williams N. Selective autonomic and sensory deficits in slow transit constipation. J Auton Nerv Syst 1997;66:46-52.

12. Park HJ, Kamm MA, Abbasi AM, Talbot IC. Immunohistochemical study of the colonic muscle and innervation in idiopathic chronic constipation. Dis Colon Rectum 1995;38:509-13.

13. Wedel T, Roblick UJ, Ott V, Eggers R, Schiedeck TH, Krammer HJ, et al. Oligoneuronal hypoganglionosis in patients with idiopathic slow-transit constipation. Dis Colon Rectum 2002;45:54-62.

14. Zhao RH, Baig MK, Mack J, Abramson S, Woodhouse S, Wexner $\mathrm{SD}$. Altered serotonin immunoreactivities in the left colon of patients with colonic inertia. Colorectal Dis 2002;4:56-60.

15. Baig MK, Zhao RH, Woodhouse SL, Abramson S, Weiss JJ, Nogueras JJ, et al. Variability in serotonin and enterochromaffin cells in patients with colonic inertia and idiopathic diarrhoea as compared to normal controls. Colorectal Dis 2002;4:348-54.

16. De Ponti F, De Giorgio R. The cathartic colon? Aliment Pharmacol Ther 2002;16:643-4.

17. Redmond JM, Smith GW, Barofsky I, Ratych RE, Goldsborough DC, Schuster MM. Physiological tests to predict long-term outcome of total abdominal colectomy for intractable constipation. Am J Gastroenterol 1995;90:748-53.

18. Pemberton JH, Rath DM, Ilstrup DM. Evaluation and surgical treatment of severe chronic constipation. Ann Surg 1991;214:403-11.

19. Glia A, Akerlund JE, Lindberg G. Outcome of colectomy for slowtransit constipation in relation to presence of small-bowel dysmotility. Dis Colon Rectum 2004;47:96-102.

20. Vasilevsky CA, Nemer FD, Balcos EG, Christenson CE, Goldberg SM. Is subtotal colectomy a viable option in the management of chronic constipation? Dis Colon Rectum 1988;31:679-81.

21. Nyam DC, Pemberton JH, Ilstrup DM, Rath DM. Long-term results of surgery for chronic constipation. Dis Colon Rectum 1997;40: 273-9.

22. Beck DE, Jagelman DG, Fazio VW. The surgery of idiopathic constipation. Gastroenterol Clin North Am 1987;16:143-56.

23. Nicholls RJ, Kamm MA. Proctocolectomy with restorative ileoanal reservoir for severe idiopathic constipation. Report of two cases. Dis Colon Rectum 1988;31:968-9.

24. Riss S, Herbst F, Birsan T, Stift A. Postoperative course and long term follow up after colectomy for slow transit constipation--is surgery an appropriate approach? Colorectal Dis 2009;11:302-7.

25. Zutshi M, Hull TL, Trzcinski R, Arvelakis A, Xu M. Surgery for slow transit constipation: are we helping patients? Int J Colorectal Dis 2007;22:265-9.

26. Knowles CH, Scott M, Lunniss PJ. Outcome of colectomy for slow transit constipation. Ann Surg 1999;230:627-38.

27. Pikarsky AJ, Singh JJ, Weiss EG, Nogueras JJ, Wexner SD. Longterm follow-up of patients undergoing colectomy for colonic inertia. Dis Colon Rectum 2001;44:179-83.

28. FitzHarris GP, Garcia-Aguilar J, Parker SC, Bullard KM, Madoff RD, Goldberg SM, et al. Quality of life after subtotal colectomy for slow-transit constipation: both quality and quantity count. Dis Colon Rectum 2003;46:433-40.

29. Pinedo G, Zarate AJ, Garcia E, Molina ME, Lopez F, Zuniga A. Laparoscopic total colectomy for colonic inertia: surgical and functional results. Surg Endosc 2009;23:62-5.

30. Piccirillo MF, Reissman P, Wexner SD. Colectomy as treatment for constipation in selected patients. Br J Surg 1995;82:898-901.

31. Platell C, Scache D, Mumme G, Stitz R. A long-term follow-up of patients undergoing colectomy for chronic idiopathic constipation. Aust N Z J Surg 1996;66:525-9.

32. Lubowski DZ, Chen FC, Kennedy ML, King DW. Results of colectomy for severe slow transit constipation. Dis Colon Rectum 1996; 39:23-9.

33. Bernini A, Madoff RD, Lowry AC, Spencer MP, Gemlo BT, Jensen LL, et al. Should patients with combined colonic inertia and nonrelaxing pelvic floor undergo subtotal colectomy? Dis Colon Rectum 1998;41:1363-6.

34. Hasegawa H, Radley S, Keighley MRB. Long-term results of colorectal resection for chronic constipation [abstract]. Association of Coloproctology of Great Britain and Ireland conference proceedings 1998. Oxford: Blackwell Science; 1998.

35. Hassan I, Pemberton JH, Young-Fadok TM, You YN, Drelichman ER, Rath-Harvey D, et al. Ileorectal anastomosis for slow transit constipation: long-term functional and quality of life results. J Gastrointest Surg 2006;10:1330-6. 